\title{
Ueber \\ Derivate der Hydrazinisobuttersäure.
}

\section{Inaugural - Dissertation}

Erlangung der Doktorwürde

der

hohen philosophisehen Fakultăt

der

Kgl. bayer. Ludwig-Maximilians-Universität zu München

vorgelegt von

Christian Frank

aus Coburg.

München

Druck von Val. Höfling, Kapellenstrasse Nr. 3

1898. 



\section{Meiner Mutter}

in Liebe und Dankbarkeit gewidmet. 

Es sei mir auch an dieser Stelle gestattet, Herrn Professor Dr. Joh. Thiele, unter dessen licbenswürdiger Leitung vorliegende Arbeit ausgeführt wurde, sowie meinem hochverehrten Lehrer, Herrn Geheimrat Professor Dr. A. v. Ba e y e r meinen verbindlichsten Dank auszusprechen. 
